\title{
Efeitos do FUNDEF/B sobre Frequência Escolar, Fluxo Escolar e Trabalho Infantil: Uma Análise com Base nos Cen- sos de 2000 e 2010 *
}

\section{Gabriela Cruz}

Tecnologista (Economia) - Instituto Brasileiro de Geografia e Estatística (IBGE)

Endereço: Av. Chile, 500 - Centro - Rio de Janeiro /RJ

CEP: 20031-170 - E-mail: gabriela.cruz@ppge.ie.ufrj.br

\section{Rudi Rocha}

Professor - Universidade Federal do Rio de Janeiro

Endereço: Av. Pasteur, 250 - Urca - Rio de Janeiro /RJ

CEP: 22290-902 - E-mail: rudi.rocha@ie.ufrj.br

Recebido: 09/08/2016. Aceite: 15/09/2017.

\section{Resumo}

Este artigo avalia os impactos do FUNDEF e FUNDEB sobre frequência escolar, distorção idade-série e trabalho infantil das crianças expostas a esses recursos durante idade escolar. Estimamos regressões com efeitos-fixos de municípios e coortes com base nos microdados dos Censos de 2000 e 2010, e nos gastos municipais do FINBRA de 1993 a 2010. Considerando municípios com proporção de matrículas na rede municipal igual à mediana, encontramos que um aumento de R\$100 per capita nas transferências destes fundos está relacionado a um aumento da probabilidade de uma criança frequentar escola de 0,05 pontos percentuais, e a uma diminuição da distorção idade-série em 0,02 anos. Esses resultados equivalem a efeitos de, respectivamente, $1 \%$ e 6,5\% de um desvio-padrão nestas variáveis frente a um aumento das transferências líquidas de um desvio-padrão (R\$385 per capita). Identificamos ainda que os efeitos são maiores para crianças com perfil socioeconômico mais baixo. Os efeitos sobre trabalho infantil são geralmente próximos de zero.

\section{Palavras-Chave}

Educação. Gasto público. Fluxo escolar. Trabalho infantil.

\begin{abstract}
This paper evaluates the impact of FUNDEF and FUNDEB on school enrolment, age to grade distortion and child labor of children exposed to financial resources during their school age. We estimate regressions with fixed effects for municipalities and cohorts using microdata from the 2000 and 2010 Censuses and data on local government spending from FINBRA between 1993 and 2010. For municipalities where the share of students attending local schools is equal to the median, an increase of R\$100 per capita in transfers is related to an increase in 0.05 percentage points in school attendance, and to a reduction on age to grade distortion of 0.02 years. These effects are equivalent to $1 \%$ and $6.5 \%$ of standard deviation, respectively, when

- Agradecemos os comentários de Valéria Pero e Fábio Waltenberg que participaram da banca de dissertação que deu origem a este artigo. Agradecemos também a Maíra Franca, Elaine Pazello, Gabriel Ulyssea e Sol Garson.
\end{abstract}

(7) () Esta obra está licenciada com uma Licença Creative Commons Atribuição-Não Comercial 4.0 Internacional. 
transfers increase by one standard deviation (R\$385 per capita). We also identify stronger effects for children of low socioeconomic status. Effects on child labour are generally null.

\section{Keywords}

Education. Government expenditure. School enrollment. Child labor.

\section{JEL Classification}

122. 128.

\section{Introdução}

A Constituição de 1988 estabeleceu que 18\% das receitas da União e 25\% das receitas dos estados e municípios, incluindo apenas aquelas provenientes de impostos e transferências, deveriam ser destinadas à educação. Devido à falta de vinculação dessas receitas para fins específicos e à pouca fiscalização, os recursos tendiam a ser mal aplicados ou mesmo direcionados a outras áreas. Ademais, manteve-se a desigualdade de recursos entre municípios e Unidades da Federação. Em 1998, o Governo Federal introduziu o Fundo de Manutenção e Desenvolvimento do Ensino Fundamental e de Valorização do Magistério (FUNDEF), que alterou a distribuição de recursos entre estados e municípios com o intuito de promover maior equidade em gastos educacionais no Ensino Fundamental. Em 2006, a Emenda Constitucional 53/2006 substituiu o FUNDEF pelo Fundo de Manutenção e Desenvolvimento da Educação Básica e de Valorização dos Profissionais da Educação (FUNDEB), implementado em 2007. O FUNDEB passou a incluir toda a Educação Básica (creche e pré-escola, Ensino Fundamental, Ensino Médio e Educação de Jovens e Adultos (EJA)). Com isso, ampliouse a proporção dos impostos e transferências destinada ao fundo, e incorporaram-se novas fontes de receita e novos pisos mínimos para gastos educacionais per capita. A introdução do FUNDEF/FUNDEB pode ser considerada uma das mais importantes mudanças no regime de financiamento da educação básica brasileira. Em particular, a implantação destes fundos induziu a expansão do gasto educacional em municípios mais pobres.

O presente artigo contribui para a literatura ao estimar os impactos dos fundos de financiamento da educação básica sobre resultados educacionais 
e trabalho infantil a partir dos Censos Demográficos de 2000 e 2010, o que nos permite avaliar efeitos sobre a margem extensiva da demanda educacional (frequência e fluxo) e ocupação das crianças no mercado de trabalho. A literatura empírica existente sobre os impactos do FUNDEF/ FUNDEB aponta, em geral, para efeitos positivos, embora pequenos, sobre matrícula e fluxo escolar; e efeitos não conclusivos sobre desempenho. No entanto, os estudos existentes têm utilizado microdados do sistema educacional disponibilizados pelo MEC/INEP, o que, por consequência, não nos permite compreender o que ocorre justamente com as crianças (e famílias) que estão fora dos registros escolares e, portanto, fora da escola e eventualmente no mercado de trabalho (ver, por exemplo, Gordon e Vegas 2004; Menezes-Filho e Pazello 2007; Franco e Menezes-Filho 2010; Franca 2013). Neste artigo, nos concentramos sobre o impacto dos fundos sobre frequência escolar, distorção idade-série e trabalho infantil a partir dos microdados dos Censos Demográficos, que nos fornecem o universo das crianças. Ainda, isso nos permite identificar não apenas o efeito dos fundos sobre a margem extensiva da demanda educacional (frequência e fluxo) e sobre trabalho infantil, como também caracterizar heterogeneidades do efeito para perfis socioeconômicos distintos de famílias e crianças. Também nos permite documentar em que medida existe viés de seleção sobre frequência escolar após a introdução dos fundos, e eventualmente conciliar as evidências existentes que indicam expansão de matrículas e ausência de melhorias em proficiência.

Para tanto, vamos explorar a exposição das crianças à variação de recursos educacionais entre municípios de residência e coortes de nascimento ao longo do tempo. A variável de interesse consiste na exposição dos indivíduos ao FUNDEF/FUNDEB durante os anos em que tinham idade adequada para cursar o Ensino Fundamental. Ela é igual à diferença entre as contribuições e os recursos recebidos destes fundos pelo município onde a criança vive. A base Finanças do Brasil (FINBRA), da Secretaria do Tesouro Nacional, contém essas informações. Já as informações ao nível das crianças são obtidas a partir dos Censos Demográficos de 2000 e 2010. Para avaliar os impactos do FUNDEF/FUNDEB sobre as variáveis de resultado, estimamos modelos ao nível das crianças, com efeitos fixos de município, idade e ano do Censo. Estes dois últimos, em conjunto, identificam a coorte à qual a criança pertence. A hipótese de identificação é que, condicional a esses efeitos fixos e controles adicionais de características observáveis, a variação remanescente na variável de interesse é ortogonal a toda e qualquer variação em determinantes latentes das variáveis de re- 
sultado. Essa estratégia é similar à utilizada em outros estudos do gênero, como, por exemplo, Duflo (2001) e Chetty, Friedman e Rockoff (2013).

Como os dados dizem respeito apenas às finanças municipais e os Censos Demográficos não trazem informação sobre a rede de ensino na qual o indivíduo estuda ou estudou, espera-se que os efeitos investigados variem de acordo com a importância da rede municipal na oferta do Ensino Fundamental no município. Para considerar essa fonte de heterogeneidade, incluímos uma interação entre a variável de interesse e a proporção de matrículas na rede municipal no município no ano base, no caso 1995, o primeiro ano para o qual temos essa informação. Assim, exploramos o efeito por cobertura da rede municipal de ensino, e documentamos em que medida o processo de descentralização na oferta educacional durante o período de análise beneficiou ou limitou a eficácia do FUNDEF/FUNDEB sobre os resultados educacionais.

Outra fonte de heterogeneidade investigada é o background familiar das crianças, que, em geral, é apontado como o principal determinante dos resultados educacionais (Barros et al. 2001). Os efeitos das políticas podem ser mais fortes sobre aquelas que têm background mais pobre (menor renda ou pais menos escolarizados, por exemplo) se atuarem em um sentido de equalizar resultados; ou podem ter efeitos mais fracos, se o ambiente difícil em que a criança está inserida for um obstáculo à absorção dos efeitos da política. Essas hipóteses são investigadas acrescentando à regressão uma interação da variável de interesse com uma dummy que identifica se o responsável pelo domicílio tem ou não ensino fundamental completo.

Os resultados revelam efeitos positivos do aumento dos recursos transferidos via FUNDEF/FUNDEB. Considerando municípios cuja proporção de matrículas na rede municipal é igual à mediana (27\% em 1995), um aumento das transferências líquidas do FUNDEF/FUNDEB de R $\$ 100$ per capita está relacionado a um aumento da probabilidade de uma criança frequentar escola em 0,05 pontos percentuais, enquanto a distorção idade-série média cai 0,02 anos. Esses resultados equivalem a um impacto de, respectivamente, $0,9 \%$ e $6,5 \%$ de um desvio-padrão frente a um aumento das transferências líquidas de um desvio-padrão (aproximadamente $\mathrm{R} \$ 385)$. O efeito sobre a probabilidade da criança trabalhar é próximo de zero. Já em municípios onde a totalidade das matrículas pertence à rede municipal, os efeitos são bem mais expressivos. Um aumento de R \$100 nas transferências líquidas do FUNDEF/FUNDEB implica um crescimento de 
0,3 pontos percentuais na probabilidade de frequentar escola, e uma redução da distorção idade-série de 0,09 anos. Sobre a diferença entre crianças cujo responsável pelo domicílio tem ou não ensino fundamental completo, os resultados revelam que os efeitos positivos tendem a ser mais fortes para aquelas de background familiar mais pobre. Para elas, o aumento do FUNDEF/FUNDEB líquido per capita de R \$100 causa um aumento da frequência escolar de 0,07 pontos percentuais e uma redução da defasagem de 0,03 anos, considerando a proporção de matrículas municipais mediana. Ou seja, além dos efeitos totais positivos sobre os indicadores de frequência e fluxo, o FUNDEF/FUNDEB também teve impactos importantes na redução das desigualdades dos indicadores entre as crianças.

Os resultados encontrados, portanto, avançam em algumas direções importantes. Em primeiro lugar, confirmamos um efeito positivo sobre frequência e fluxo escolar. Os efeitos sobre trabalho infantil são menos significativos. Observamos também que os efeitos sobre frequência e fluxo escolar são relativamente mais fortes entre as crianças mais pobres. Por um lado, esse fato é relevante em si, já que indica que os fundos resultaram em mais equidade. Por outro lado, tal fato sugere viés de seleção na amostra dos alunos que realizam provas de proficiência, uma vez que revela que a frequência escolar aumenta mais entre os mais pobres, que tendem a ter pior desempenho. Dessa forma, concilia expansão de matrículas e ausência de melhorias de performance acadêmica.

Além de contribuir diretamente para a literatura nacional sobre os impactos do FUBDEF/FUNDEB, este artigo ainda está relacionado a artigos internacionais que examinam a relação entre disponibilidade de recursos para educação e resultados educacionais, objeto de estudo há bastante tempo. Coleman et al. (1966) questionou a existência de uma correlação positiva entre essas variáveis nos Estados Unidos na década de 1960, atribuindo o desempenho dos alunos principalmente ao background familiar. Desde então, muitos estudos foram feitos na área, com resultados inconclusivos. Krueger (2002) e Hanushek (2003) revisam uma ampla literatura existente até os anos 2000 e discordam a respeito da existência de impactos positivos do aumento do gasto em educação sobre os resultados de crianças e adolescentes. Gibbons e McNally (2013), por sua vez, concluem que os estudos mais recentes, com estratégias de identificação melhores, têm encontrado efeitos positivos, embora pequenos. Uma conclusão comum à maior parte desses estudos é que os impactos são maiores entre os estudantes com maiores defasagens. 
A alteração de regras de distribuição de recursos entre localidades é uma importante fonte de variação exógena dos gastos em educação e vem sendo amplamente utilizada por essa literatura. Cascio e Reber (2013) mostram que o programa Tite I, que transfere recursos para estados mais pobres dos Estados Unidos, reduziu a diferença entre o gasto por criança dos estados ricos e pobres, embora esta tenha se mantido expressiva. Roy (2011) revela um efeito positivo do plano Proposal $A$, que promoveu uma profunda reforma no sistema de financiamento da educação no estado norte-americano de Michigan em 1994. O artigo mostra que o plano teve êxito em promover uma maior equalização do gasto entre os distritos, o que teve efeitos positivos no desempenho dos alunos em testes dos distritos de baixo gasto. Jackson, Johnson e Persico (2016) também encontram efeitos positivos do aumento dos gastos educacionais induzido pelas reformas nas formas de financiamento da educação nos Estados Unidos sobre os resultados dos indivíduos, inclusive no longo-prazo (salário, escolaridade e incidência da pobreza). Os efeitos positivos estariam associados a melhorias dos insumos escolares, com redução do número de alunos por professor, aumento dos salários dos professores e extensão da duração dos anos letivos.

Este artigo está dividido em seis seções, sendo a primeira esta introdução. A Seção 2 descreve o contexto institucional e apresenta uma revisão da literatura sobre o tema. Em seguida, apresentamos e fazemos uma análise descritiva dos dados utilizados neste artigo. A Seção 4 descreve a estratégia empírica, enquanto que a Seção 5 apresenta os resultados. A sexta e última seção apresenta as considerações finais.

\section{Contexto Institucional}

\subsection{Fundos de Financiamento da Educação Básica no Brasil: FUNDEF e FUNDEB}

A Constituição de 1988 estabeleceu que 18\% das receitas da União e 25\% das receitas dos estados e municípios, incluindo apenas aquelas provenientes de impostos e transferências, deveriam ser destinadas à educação. Devido à falta de vinculação dessas receitas para fins específicos e à pouca fiscalização, os recursos tendiam a ser mal aplicados ou mesmo direcionados a outras áreas. Ademais, manteve-se a desigualdade de recursos entre 
municípios e Unidades da Federação. De acordo com Franco e MenezesFilho (2010), "a heterogeneidade observada nas escolas se agravou porque estados e municípios com diferentes demandas por educação apresentavam recursos e gastos por alunos que variavam diretamente à renda per capita da região e inversamente à demanda por educação pública na mesma" (Franco e Menezes-Filho 2010, 4).

Em 1998, o Governo Federal implantou o Fundo de Manutenção e Desenvolvimento do Ensino Fundamental e de Valorização do Magistério (FUNDEF), que alterava a distribuição de recursos entre estados e municípios com o intuito de promover maior equidade. A Emenda Constitucional $n^{\circ} 14 / 96$, cuja vigência prevista era de 10 anos, estabeleceu que $60 \%$ de alguns dos recursos estaduais e municipais já vinculados à educação, e que antes eram gastos diretamente por cada governo em sua própria rede de ensino, seriam transferidos para fundos estaduais. Conforme apresentado no Quadro 1, municípios e estados transferiam para o fundo da respectiva Unidade da Federação 15\% das receitas provenientes das seguintes fontes: Fundo de Participação dos Estados (FPE); Fundo de Participação dos Municípios (FPM); Imposto sobre Circulação de Mercadorias e Serviços (ICMS); Imposto sobre Produtos Industrializados, proporcional às exportações (IPlexp); e Desoneração de exportações (Lei Complementar $n^{\circ}$ 87/96).

Quadro 1 - Fontes de Recursos do FUNDEF e FUNDEB 


\begin{tabular}{|c|c|}
\hline $15 \%$ de contribuição de estados, DF e municípios sobre: & $\begin{array}{l}16,25 \%, 17,50 \%, 18,75 \% \text { e } 20 \% \text { no } 1^{\circ}, 2^{\circ}, 3^{\circ} \text { e a partir do } \\
4^{\circ} \text { ano, respectivamente de contribuição de estados, DF e } \\
\text { municípios sobre: }\end{array}$ \\
\hline - Fundo de Participação dos Estados - FPE & - Fundo de Participação dos Estados - FPE \\
\hline . Fundo de Participação dos Municípios - FPM & - Fundo de Participação dos Municípios - FPM \\
\hline $\begin{array}{l}\text { Imposto sobre Circulação de Mercadorias e Serviços } \\
\text { - ICMS }\end{array}$ & $\begin{array}{l}\text { - Imposto sobre Circulação de Mercadorias e Serviços } \\
\text { - ICMS }\end{array}$ \\
\hline $\begin{array}{l}\text { Imposto sobre Produtos Industrializados, proporcional } \\
\text { às exportações - IPlexp }\end{array}$ & $\begin{array}{l}\text { Imposto sobre Produtos Industrializados proporcional } \\
\text { às exportações - IPlexp }\end{array}$ \\
\hline \multirow[t]{5}{*}{ - Desoneração de Exportações (LC 87/96) } & · Desoneração de Exportações (LC 87/96) \\
\hline & $\begin{array}{l}5 \%, 10 \%, 15 \% \text { e } 20 \% \text { no } 1^{\circ}, 2^{\circ}, 3^{\circ} \text { e a partir do } 4^{\circ} \text { ano, } \\
\text { respectivamente de contribuição de estados, DF e } \\
\text { municípios sobre: }\end{array}$ \\
\hline & $\begin{array}{l}\text { - Imposto sobre Transmissão Causa Mortis e Doações } \\
\text { - ITCMD }\end{array}$ \\
\hline & $\begin{array}{l}\text { - Imposto sobre Propriedade Veículos Automotores - } \\
\text { IPVA }\end{array}$ \\
\hline & $\begin{array}{l}\text { Quota Parte de } 50 \% \text { do Imposto Territ. Rural devida } \\
\text { aos Municípios - ITR }\end{array}$ \\
\hline Complementação da União & Complementação da União \\
\hline
\end{tabular}

Notas: Elaboração própria.

O dinheiro arrecadado por cada Unidade da Federação deveria ser redistribuído entre seus municípios e o governo estadual de acordo com o número de matrículas no Ensino Fundamental de cada rede. O montante recebido por cada governo deveria ser, obrigatoriamente, gasto no Ensino Fundamental. Essa nova forma de distribuição dos recursos pode ser tomada como exógena porque não depende das receitas e, consequentemente, da renda per capita de cada município individualmente. Também não está relacionada às escolhas dos governantes em relação à alocação dos recursos disponíveis. Ademais, ela iguala o gasto por aluno (ao menos aquele advindo das receitas do FUNDEF) dentro de cada estado, gerando uma variação de recursos interessante do ponto de vista de avaliação de políticas públicas: municípios com características distintas, mas que se localizam na mesma Unidade da Federação, terão o mesmo montante de recursos por aluno; enquanto municípios parecidos, mas de estados diferentes, poderão ter acesso a quantidades bem distintas de recursos. 
Em 2006, a Emenda Constitucional no 53/2006 substituiu o FUNDEF pelo Fundo de Manutenção e Desenvolvimento da Educação Básica e de Valorização dos Profissionais da Educação (FUNDEB), implementado em 2007 com prazo de duração de 14 anos. O FUNDEB passou a incluir toda a Educação Básica (creche e pré-escola, Ensino Fundamental, Ensino Médio e Educação de Jovens e Adultos (EJA)). Com isso, ampliou-se a proporção dos impostos e transferências destinados ao fundo e incorporaram-se novas fontes de receita. Outros impostos, como o Imposto Predial e Territorial Urbano (IPTU) e o Imposto sobre Serviços (ISS), estão vinculados à educação, mas não compõem os fundos. Dessa forma, ainda existe alguma desigualdade do gasto por aluno mesmo entre os municípios de um mesmo estado. Há ainda um montante de recursos de complementação da União, transferidos pelo Governo Federal para que aquelas Unidades da Federação cuja arrecadação do fundo é insuficiente para garantir um gasto mínimo por aluno consigam atingi-lo. O Gráfico 1 apresenta os valores mínimos para o Ensino Fundamental estabelecidos em cada ano, ao longo do tempo.

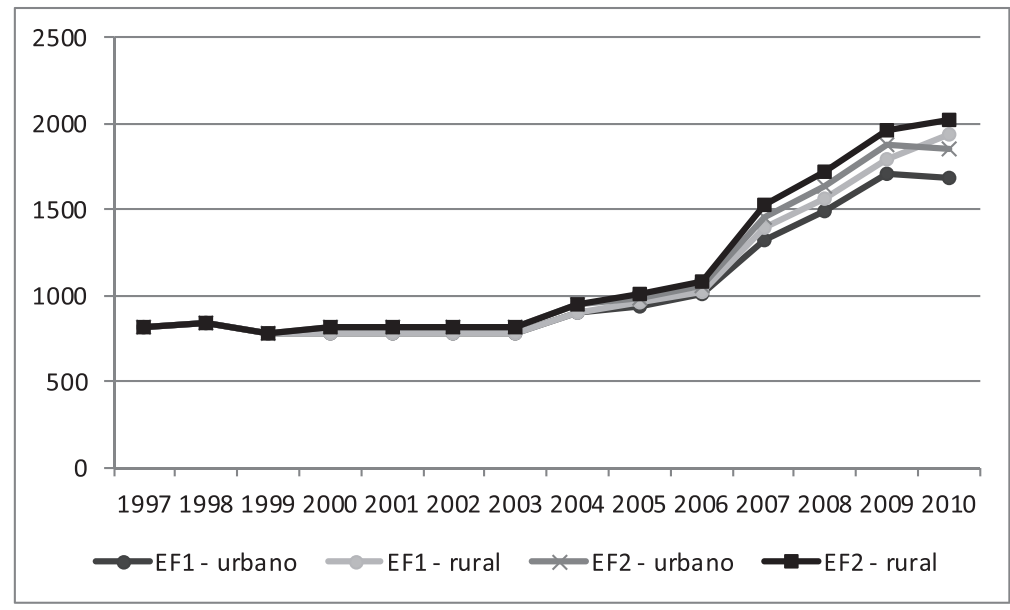

Gráfico 1 - Valor mínimo anual por aluno (em R\$2013)

Notas: Elaboração própria a partir dos decretos anuais da Presidência da República referentes ao FUNDEF e FUNDEB. Os valores de 1997 correspondem ao que foi definido na lei complementar 14/96, embora o fundo tivesse sido implementado apenas no Pará neste ano.

Como se observa, até 1999 não há diferenciação dos valores transferidos por aluno do Ensino Fundamental. Em termos reais, observa-se uma estagnação do valor mínimo por aluno até 2003, havendo anos em que este 
mínimo por aluno cai um pouco. O fato desse valor não ser atualizado sequer pela inflação fez com que, ao longo desses anos, as transferências da União diminuíssem (Guimarães 2005). A partir de então os valores passam a crescer progressivamente.

O FUNDEF e o FUNDEB também estabeleceram usos diferentes para seus recursos. No caso do FUNDEF, 60\% deles deveriam ser destinados à remuneração e à capacitação dos professores, e não foi estabelecido nenhum piso salarial nacional. Já o FUNDEB estabeleceu que $60 \%$ dos recursos deveriam ser empregados apenas na remuneração dos professores. Ademais, em 2008, a lei no 11.738 estabeleceu o piso salarial nacional de $\mathrm{R} \$ 950$, valor este atualizado anualmente (em janeiro de 2017, este valor foi atualizado para $\mathrm{R} \$ 2.298,80$ ).

\subsection{Impactos do FUNDEF e FUNDEB sobre os Resultados Educacionais}

A variação dos recursos educacionais causada pelo FUNDEF foi usada por muitos estudos para investigar a relação entre gastos em educação e desempenho escolar dos alunos. Gordon e Vegas (2005) analisam os impactos do FUNDEF sobre os gastos, insumos educacionais e resultados dos estudantes usando dados de 1996 a 2002. Como variável instrumental para os gastos com educação, os autores utilizam a receita de cada estado ou município vinculada à educação: $25 \%$ de todos os impostos e transferências até 1998, quando o FUNDEF foi implementado; e 10\% dos impostos e transferências vinculados ao fundo, mais $25 \%$ dos impostos e transferências não vinculados ao fundo, mais o montante recebido do fundo após sua criação. Este instrumento é forte, mas dificilmente válido, pois inclui as receitas vinculadas à educação, que são correlacionadas com o nível de renda do município. Os modelos estimados sugerem que o aumento dos gastos resultante do FUNDEF aumenta um pouco a frequência escolar no Ensino Fundamental II e reduz o tamanho das turmas. As turmas menores causam uma redução da distorção idade-série, estatisticamente significativa no Fundamental I, mas, segundo o artigo, o efeito é muito pequeno diante do alto custo. Os autores também concluem que a equalização dos gastos diminui a diferença entre os alunos de alto e baixo desempenho, e que o efeito sobre as notas do SAEB é negativo, mas economicamente insignificante. 
Franco e Menezes-Filho (2010), por sua vez, encontram alguns resultados diferentes usando bases de dados semelhantes. Os autores constroem dois tipos de variáveis de interesse: o valor líquido do FUNDEF por aluno e uma dummy que identifica se o município ganhou ou perdeu recursos. Ao estimar modelos ao nível de municípios e redes com dados de 1997, 1999, 2001, 2003 e 2005, eles concluem que o FUNDEF promoveu um aumento das matrículas e da razão alunos/professor. Há, também, um crescimento do número de professores e da proporção de professores de $5^{\mathrm{a}}$ a $8^{\mathrm{a}}$ série com o $3^{\circ}$ grau completo, enquanto a proporção de professores com Ensino Superior que lecionam para turmas de $1^{\text {a }}$ a $4^{\text {a }}$ série caiu. Já o desempenho dos alunos em provas de proficiência parece ter piorado, mas os resultados são bastante sensíveis ao modelo utilizado. A hipótese dos autores é que o aumento das matrículas gerou uma redução dos recursos per capita. Outra possibilidade é o ingresso de novos alunos no Ensino Fundamental, os quais possivelmente tinham background familiar pior, ter gerado viés de seleção e atenuado o efeito médio estimado.

Nesse mesmo sentido, Franca (2013) discute o financiamento da educação no Brasil e seus impactos sobre os resultados educacionais. A autora estima um modelo de diferenças-em-diferenças a partir de um painel de municípios com informações dos anos de 2005 e 2009 para avaliar o impacto dos recursos do FUNDEB sobre o desempenho dos alunos. Em geral, os resultados sugerem um impacto negativo das transferências do FUNDEB. A própria autora, porém, aponta alguns aspectos que podem estar limitando a análise, tais como o processo de municipalização e a impossibilidade de verificar as tendências das notas dos alunos antes de 2005.

Outros autores usaram o fato de a maior parte dos recursos desses fundos serem aplicados, obrigatoriamente, na remuneração dos professores para estudar o comportamento de seus salários e seus impactos sobre o desempenho dos alunos. É o caso de Anuatti-Neto, Fernandes e Pazello (2004). Ao comparar a evolução dos salários de professores e outras categorias entre 1997 e 1999, os autores concluem que há um impacto positivo do fundo sobre os salários e que, em geral, sua implantação reduziu as desigualdades. Menezes-Filho e Pazello (2007), por sua vez, estudam a relação entre salário dos professores e desempenho dos alunos a partir das variações salariais causadas pelo FUNDEF. Os autores encontram, ao final da análise, um efeito positivo e significativo. No entanto, o efeito só aparece entre os professores que trabalham há menos tempo na mesma escola. 
Vários dos autores mencionados chamam a atenção para o fato de que muitas outras reformas educacionais foram implementadas a partir do final dos anos 90, de modo que seus efeitos podem se confundir com os do FUNDEF/FUNDEB. Franco e Menezes-Filho (2010, 2) destacam a adoção da progressão continuada em algumas redes de ensino e a exigência de curso secundário completo para professores da educação infantil e das séries iniciais do Ensino Fundamental, além do processo de descentralização que se acelerou nos últimos anos.

O processo de municipalização do ensino se iniciou ainda nos anos 50 (ver D'atri 2007; Franca 2013) e se acelerou com o FUNDEF/FUNDEB, que permitiu que municípios com poucos recursos ampliassem suas redes. Por um lado, a descentralização pode ser uma forma de melhorar a gestão, responsabilizando mais os gestores, envolvendo mais a comunidade na vida escolar e estimulando uma competição entre os municípios em busca de soluções inovadoras. Por outro, é questionável a capacidade de alguns municípios, em termos financeiros e logísticos, de administrar o sistema educacional (ver Madeira 2007). Leme, Paredes e Souza (2009) encontram efeitos negativos do processo de municipalização gerado pelo FUNDEF sobre as notas dos alunos no SAEB e Prova Brasil. D'atri (2007) utiliza dados dos Censos Escolares de 1998 a 2004 e mostra que a municipalização aumenta as taxas de abandono e a distorção idade-série, devido ao aumento do tamanho das escolas e das turmas, e à consequente atração de alunos de pior background familiar. Assim sendo, podemos estar diante de uma situação em que é difícil separar forças associadas ao FUNDEF/FUNDEB que agem em sentidos opostos: a descentralização parece ter efeito negativo sobre os resultados educacionais, enquanto espera-se que o aumento do montante de recursos tenha impacto positivo.

Os resultados encontrados até então sobre os impactos do aumento do gasto provocado pelo FUNDEF/FUNDEB apontam, em geral, para efeitos positivos, embora pequenos, sobre matrícula e fluxo escolar; e efeitos não conclusivos sobre desempenho. Em geral a literatura existente utiliza microdados do sistema educacional disponibilizados pelo MEC/INEP, o que por consequência não nos permite observar o que ocorre com crianças (e famílias) que estão fora do sistema. Neste artigo nos concentramos sobre o impacto dos fundos sobre frequência escolar, distorção idade-série e trabalho infantil a partir dos microdados dos Censos Demográficos. Isso nos permite não apenas identificar de fato o efeito dos fundos sobre a margem extensiva da demanda educacional, e sobre trabalho infantil, mas 
também caracterizar de modo completo heterogeneidades do efeito para perfis socioeconômicos distintos de famílias e crianças. Por sua vez, isso nos permite documentar se de fato existe um viés de seleção sobre frequência escolar após a introdução dos fundos.

\section{Dados}

Neste artigo, utilizaram-se duas fontes de dados principais: o FINBRA (Finanças do Brasil/STN), que traz informações autodeclaradas a respeito das receitas e despesas anuais dos municípios brasileiros; e os Censos Demográficos dos anos de 2000 e 2010. Em um primeiro momento, construímos uma base de dados de municípios ao longo dos anos, a fim de documentar a relação entre a implementação do FUNDEF/FUNDEB e as despesas educacionais dos governos municipais. Em seguida, construímos outra base cruzando informações sobre crianças de 7 a 14 anos com as finanças dos municípios onde moravam durante a idade escolar. Esta última será utilizada na avaliação dos impactos do gasto em educação sobre os resultados dos indivíduos.

\subsection{Construção das Variáveis e Seleção da Amostra}

\subsubsection{Base de Municipios}

A base de dados de municípios contém informações sobre suas respectivas finanças públicas, de 1993 a 2010. A principal fonte de dados é a base Finanças do Brasil, da Secretaria do Tesouro Nacional (FINBRA/STN). A partir dela, serão construídas as variáveis referentes aos gastos em educação e às transferências líquidas do FUNDEF/FUNDEB. A variável de interesse, "FUNDEF/FUNDEB líquido per capita", é igual a zero antes de 1998, quando não existia fundo de redistribuição dos recursos educacionais. A partir daí, é construída da seguinte maneira:

FUNDEF líquido per capita

$=\frac{(F U N D E F \text { Estado }+ \text { FUNDEF União })-\text { Contribuições para o FUNDEF }}{\text { população alvo }}$ 
O valor recebido do FUNDEF/FUNDEB é a soma do que foi recebido do fundo estadual e da complementação da União. Já a contribuição é calculada com base nos impostos que se destinam ao fundo, conforme mostrado no Quadro 1. Até 2001, essas contribuições foram calculadas de acordo com esses percentuais. ${ }^{1}$ A partir de 2002, os próprios municípios passam a declarar as deduções do FUNDEF/FUNDEB de cada fonte de receitas, de modo que os erros se tornam menores.

De 1998 a 2006, enquanto vigorou o FUNDEF, o público alvo era a população de 7 a 14 anos - isto é, em idade adequada para cursar o Ensino Fundamental. A partir daí, quando foi implementado o FUNDEB, o público alvo passou a ser a população de 4 a 17 anos, que abrange toda a Educação Básica. Os dados anuais sobre a população dos municípios estão disponíveis no DATASUS a partir de 1997. Para os anos anteriores, a população foi estimada com base na taxa de crescimento demográfico observada em cada município e faixa etária entre os anos de 1997 e 1998.

Em 1991, havia no Brasil 4.491 municípios. Em 2010, eram 5.565. No entanto, apenas 2.926 municípios declararam suas finanças em todos os anos do período considerado. Optou-se por utilizar apenas estas localidades nas estimações principais, para evitar vieses causados pela entrada e saída de municípios da base. ${ }^{2}$ Ademais, foram considerados outliers da variável de interesse os valores inferiores a $-\mathrm{R} \$ 6.000$ ou superiores a $\mathrm{R} \$ 6.000$, de modo que a base final de finanças municipais conta com 2.920 municípios ao longo de 18 anos. Além das variáveis referentes ao FUNDEF/FUNDEB, também usamos informações sobre as despesas com educação e cultura e com saúde e saneamento; e a receita vinculada à educação, igual a $25 \%$ da arrecadação com impostos e transferências. O valor per capita dessas despesas foi obtido a partir da divisão pela população de 4 a 17 anos. Por fim, algumas informações municipais foram coletadas no IPEADATA.

${ }^{1}$ Alguns municípios declaram a receita de impostos e transferências já com o desconto do FUNDEF/ FUNDEB enquanto que outros não. A fim de verificar a forma de declaração mais comum, foi selecionada uma amostra aleatória de 50 municípios para conferência no site do Banco do Brasil, onde estão descritas as transferências da União para as contas dos municípios. Verificou-se que, na amostra selecionada, a maior parte deles declarava as receitas sem o desconto.

2 Fizemos alguns testes que mostraram haver diferenças significativas entre aqueles que foram incluídos e os que foram excluídos da base: em geral, estes últimos são mais pobres, mas suas crianças apresentam melhores indicadores. As estimações feitas a partir da base não balanceada apresentaram resultados semelhantes, em geral, com efeitos mais fortes do que os da amostra balanceada. 


\subsubsection{Base de Indivíduos}

Para estimar os impactos dos gastos em educação sobre os resultados das crianças em idade escolar, foram empilhados os microdados dos Censos Demográficos de 2000 e 2010. Neles há informações sobre as variáveis de resultado - frequência escolar, distorção idade-série e trabalho infantil - e de controle. Foram selecionados os indivíduos de 7 a 14 anos, idade adequada para se cursar o Ensino Fundamental antes de sua ampliação para nove anos de duração; e que sempre moraram no mesmo município, assegurando que estes estiveram expostos exatamente ao montante de recursos correspondente à sua localidade. As crianças que se declararam como responsáveis pelos domicílios foram excluídas da base. A amostra total utilizada é composta por 2.995.211 indivíduos, os quais representam uma população de crianças de 7 a 14 anos de 27.788.831, considerando os anos de 2000 e 2010 juntos. Todas as estatísticas descritivas e regressões foram estimadas usando os pesos amostrais dos Censos Demográficos.

Esta base foi cruzada com a base de municípios. Para cada indivíduo, além das variáveis disponíveis nos próprios Censos, foi construída a variável "FUNDEF/FUNDEB líquido per capita médio" a partir dos dados sobre as finanças municipais. Tal variável consiste na média do valor do "FUNDEF/ FUNDEB líquido per capita" do município onde a criança vive durante os anos que ela esteve exposta a esses recursos. O mesmo cálculo de médias foi feito para a variável "receitas para a educação per capita". A definição dos anos que compõem essa média foi feita a partir da idade da criança, conforme o Quadro 2.

Quadro 2 - Período de exposição do FUNDEF/FUNDEB segundo idade da criança

\begin{tabular}{|c|c|c|}
\hline Idade & Censo 2000 & Censo 2010 \\
\hline 7 anos & 2000 & 2010 \\
\hline 8 anos & 1999 e 2000 & 2009 a 2010 \\
\hline 9 anos & 1998 a 2000 & 2008 a 2010 \\
\hline 10 anos & 1997 a 2000 & 2007 a 2010 \\
\hline 11 anos & 1996 a 2000 & 2006 a 2010 \\
\hline 12 anos & 1995 a 2000 & 2005 a 2010 \\
\hline 13 anos & 1994 a 2000 & 2004 a 2010 \\
\hline 14 anos & 1993 a 2000 & 2003 a 2010 \\
\hline
\end{tabular}

Notas: Elaboração própria. 


\subsection{Análise Descritiva}

\subsubsection{Base de Municípios}

As estatísticas descritivas da base de municípios estão na Tabela 1. No Painel A, são apresentados os valores totais, enquanto no painel B são apresentados os valores per capita. Todos os valores foram deflacionados pelo Índice Nacional de Preços do Consumidor (INPC/IBGE) de 2013. Os dados sobre despesas por função começaram a ser informados a partir de 1996, havendo menos observações para essas variáveis.

O valor médio recebido dos fundos pelos municípios em questão, considerando o valor zero para os anos anteriores a 1998, foi de $\mathrm{R} \$ 625,93$ per capita, variando de 0 a R $\$ 14.824$. Já o FUNDEF/FUNDEB líquido per capita tem média de $-\mathrm{R} \$ 1,46,{ }^{3}$ variando de $-\mathrm{R} \$ 5.870$ a $\mathrm{R} \$ 5.130$, o que revela que há muitos municípios que perdem recursos com a instituição do fundo. Finalmente, as despesas e receitas dos municípios por população de 4 a 17 anos variam bastante. No caso dos gastos com educação, elas têm média de $\mathrm{R} \$ 1.612,39$.

Como estamos utilizando dados de vários municípios ao longo do tempo, é importante que a variável de interesse, "FUNDEF/FUNDEB líquido per capita", tenha uma variabilidade grande em ambas as dimensões. O Gráfico 2 apresenta seu valor para cada município entre 1993 e 2010. Observa-se uma grande variação a partir de 1998. Em todos os anos, há uma quantidade significativa de redes municipais que perdem e que ganham recursos.

3 Considerando apenas as informações de 1998 em diante, isto é, durante o período de vigência do FUNDEF/B, a média do valor recebido per capita é igual a $\mathrm{R} \$ 866,68$, enquanto a média do valor líquido (receita - contribuição) é de - R \$ 2,02. 
Tabela 1 - Estatísticas descritivas da base de municípios

\begin{tabular}{|c|c|c|c|c|c|}
\hline Variáveis & Observações & Média & $\begin{array}{l}\text { Desvio } \\
\text { Padrão }\end{array}$ & Mínimo & Máximo \\
\hline \multicolumn{6}{|c|}{ Painel A - valores totais (em R\$ 1.000 de 2013) } \\
\hline Despesas com educação e cultura & 43.745 & 14.800 & 112.000 & 0 & 7.760 .000 \\
\hline Despesas com saúde e saneamento & 43.745 & 14.500 & 108.000 & 0 & 6.610 .000 \\
\hline Receitas vinculadas à educação & 52.560 & 11.400 & 97.500 & 0 & 7.200 .000 \\
\hline Valor recebido do FUNDEF / FUNDEB & 52.560 & 4.336 & 34.000 & 0 & 2.910 .000 \\
\hline Contribuição para o FUNDEF / FUNDEB & 52.560 & 2.942 & 19.100 & 0 & 1.730 .000 \\
\hline FUNDEF / FUNDEB líquido & 52.560 & 1.394 & 17.000 & -172.000 & 1.170 .000 \\
\hline \multicolumn{6}{|c|}{ Painel B - valores per capita (em R\$ 2013) } \\
\hline Despesas com educação e cultura & 43.745 & $1.612,39$ & $1.132,72$ & 0 & 79.410 \\
\hline Despesas com saúde e saneamento & 43.745 & $1.223,72$ & $1.069,29$ & 0 & 69.524 \\
\hline Receitas vinculadas à educação & 52.560 & $1.220,63$ & $1.029,86$ & 0 & 34.628 \\
\hline Valor recebido do FUNDEF / FUNDEB & 52.560 & 625,93 & 596,62 & 0 & 14.824 \\
\hline FUNDEF / FUNDEB líquido & 52.560 & $-1,46$ & 640 & -5.870 & 5.130 \\
\hline \multicolumn{6}{|c|}{ Painel C - Dummies } \\
\hline $\begin{array}{l}\text { Municípios que ganharam recursos do } \\
\text { FUNDEF / FUNDEB }\end{array}$ & 52.560 & 0,3998 & 0,4899 & 0 & 1 \\
\hline
\end{tabular}

Notas: Elaboração própria a partir dos dados do FINBRA (1993 - 2010) e Datasus.

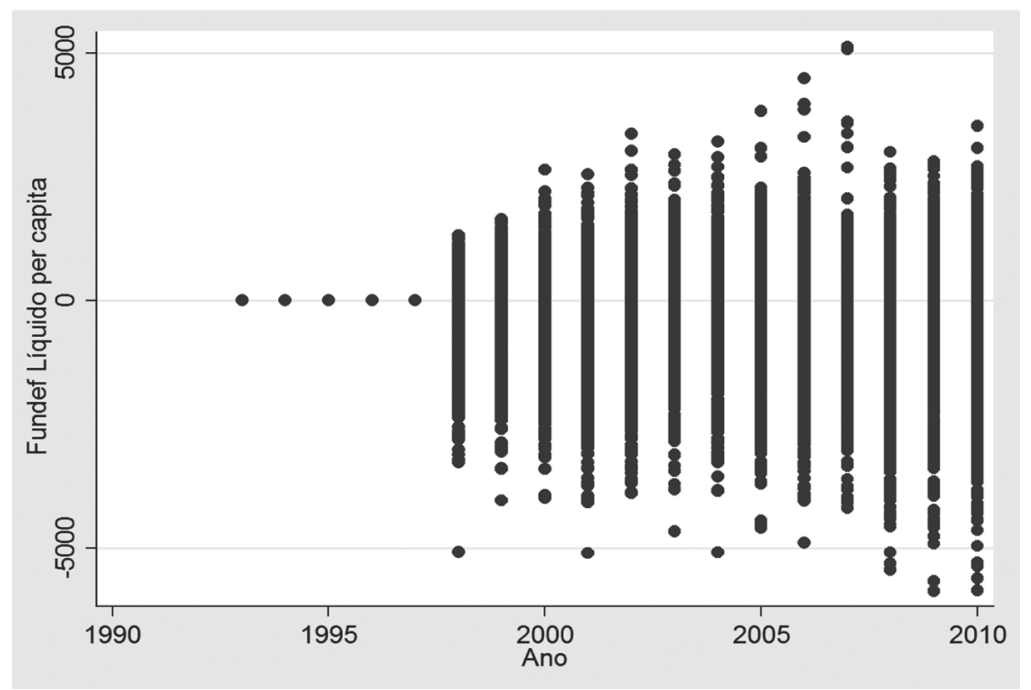

Gráfico 2 - FUNDEF líquido per capita por município e ano

Notas: Elaboração própria a partir dos dados do FINBRA (1993 - 2010) e Datasus. 
Até 1998, cada município aplicava na educação apenas os recursos dos quais dispunha. A partir da criação do FUNDEF, alguns ganham e outros perdem recursos, tanto para outros municípios da mesma Unidade da Federação, quanto para os próprios governos estaduais. Na média, o "FUNDEF/FUNDEB líquido per capita" é negativo até 2001, o que significa que as redes municipais tendiam a perder dinheiro para as redes estaduais onde estavam matriculados mais alunos do Ensino Fundamental. A partir de 2002, o valor desta variável torna-se positivo, embora não muito alto se comparado ao montante das despesas com educação. A correlação desta variável com as despesas em educação ao longo do tempo é positiva, mas não muito forte. Para verificar se o FUNDEF/B representa um choque de recursos sobre as despesas com educação, estimamos a correlação de ambas com base nos dados municipais ao longo do tempo, condicionada aos controles que serão usados nos modelos de regressão. Para tanto, estimase o seguinte modelo a partir do painel de municípios ao longo dos anos:

desp.educ.e cult.pc

$$
\begin{aligned}
& =\beta_{0}+\beta_{1} F U N D E F(B) \text { líq.pc } c_{i t}+\beta_{2} \text { receita educ.pc } c_{i t}+X_{i t} \gamma+\delta_{t} \\
& +\theta_{i}+\varepsilon_{i t}
\end{aligned}
$$

Onde i indexa municípios e t o ano. "desp.educ.e cult. $p c_{i t}$ " é a despesa municipal com educação e cultura per capita; "FUNDEF(B)líq. $p c_{i t}$ " é o valor líquido per capita recebido pelo município via FUNDEF ou FUNDEB; e "receita educ. $p c_{i t}$ " corresponde ao valor que os municípios devem, obrigatoriamente, destinar à educação, dividido pelo público alvo da educação básica. O termo $X_{i t}$ é um vetor de variáveis de controle: população, PIB per capita, participação da agricultura no valor adicionado (\%) e participação da indústria no valor adicionado (\%) do município; e PIB per capita da Unidade da Federação. Os dados referentes a alguns desses controles só estão disponíveis a partir de 1999, de modo que eles só foram usados nas amostras pós 2001. Os termos $\delta_{t}$ e $\theta_{i}$ captam os efeitos fixos de tempo e município, enquanto $\varepsilon_{i t}$ é o termo de erro, no qual estão incluídos todos os demais fatores que afetam as despesas com educação.

A Tabela 2 apresenta os resultados de cinco modelos, dois para o período de 1996 a 2010, controlando e não controlando pelas receitas vinculadas à educação per capita; e três para o período de 2002 a 2010, quando os dados têm supostamente menos problemas de declaração. $\mathrm{O}$ controle pelas receitas vinculadas à educação é necessário porque apenas parte delas é destinada ao FUNDEF/FUNDEB. Municípios pobres, que em geral gastam menos com 
educação, tendem a ganhar recursos via esses fundos aqui estudados; e municípios ricos, com mais receitas extras para gastar em educação, tendem a perder. Caso ele não fosse feito, a variável de interesse deixaria de ser exógena. Todos os modelos foram estimados com erros-padrão robustos à autocorrelação serial ao nível do município, ao longo do tempo.

Tabela 2 - Efeito do valor do FUNDEF/B sobre despesas

\begin{tabular}{|c|c|c|c|c|c|}
\hline & $(1)$ & (2) & (3) & (4) & (5) \\
\hline \multicolumn{6}{|c|}{ Painel A: Despesas em educação e cultura per capita x FUNDEF líquido per capita } \\
\hline \multirow{2}{*}{$\begin{array}{l}\text { FUNDEF/ } \\
\text { FUNDEB }\end{array}$} & 0,2076 & 0,4097 & 0,2335 & 0,2335 & 0,4068 \\
\hline & $(0,0505)^{\star \star \star}$ & $(0,0747)^{\star \star *}$ & $(0,0651)^{\star * *}$ & $(0,0651)^{\star \star *}$ & $(0,0873)^{\star * \star}$ \\
\hline \multirow{2}{*}{ Receitas } & & 0,8273 & & & 0,7978 \\
\hline & & $(0,1799)^{\star \star \star}$ & & & $(0,2019)^{\star \star \star}$ \\
\hline № obs & 43.745 & 43.745 & 41.589 & 41.589 & 41.589 \\
\hline № de municípios & 2.920 & 2.920 & 4.621 & 4.621 & 4.621 \\
\hline $\mathrm{R}^{2}$ & 0,6772 & 0,772 & 0,6982 & 0,6982 & 0,7762 \\
\hline \multicolumn{6}{|c|}{ Painel B: Despesas em saúde e saneamento per capita x FUNDEF líquido per capita } \\
\hline \multirow{2}{*}{$\begin{array}{l}\text { FUNDEF/ } \\
\text { FUNDEB }\end{array}$} & $-0,1888$ & 0,0389 & $-0,1491$ & $-0,1491$ & 0,0354 \\
\hline & $(0,0505)^{\star \star *}$ & $-0,0677$ & $(0,0642)^{\star *}$ & $(0,0642)^{\star *}$ & $(0,0814)$ \\
\hline \multirow[t]{2}{*}{ Receitas } & & 0,9321 & & & 0,8492 \\
\hline & & $(0,1653)^{\star \star \star}$ & & & $(0,1935)^{\star \star \star}$ \\
\hline № obs & 43.745 & 43.745 & 41.589 & 41.589 & 41.589 \\
\hline № de municípios & 2.920 & 2.920 & 4.621 & 4.621 & 4.621 \\
\hline $\mathrm{R}^{2}$ & 0,6834 & 0,8185 & 0,7317 & 0,7317 & 0,8311 \\
\hline Controles & Não & Não & Não & Sim & Sim \\
\hline Período & 1996 a 2010 & 1996 a 2010 & 2002 a 2010 & 2002 a 2010 & 2002 a 2010 \\
\hline
\end{tabular}

Notas: Elaboração própria a partir dos dados do FINBRA (1993 - 2010), Datasus e IPEADATA. Todas as especificações incluem efeitos fixos de ano e município. As variáveis de controle consideradas são o logaritmo natural da população, o logaritmo natural do PIB per capita, a proporção do valor adicionado da agropecuária em relação ao total, a proporção do valor adicionado da indústria em relação ao total, e o logaritmo natural do PIB per capita da Unidade da Federação onde o município se localiza. Erros-padrão entre parênteses e nível de significância indicado: ${ }^{* * *} \mathrm{p}<0,01,{ }^{* *} \mathrm{p}<0,05,{ }^{*} \mathrm{p}<0,1$.

Todos os modelos identificam um impacto positivo e significativo desta variável sobre os gastos em educação. Como esperado, esse efeito torna-se mais forte quando se controlam as receitas vinculadas à educação. Os resultados não mudam muito quando os modelos são estimados para o período de 2002 a 2010, para uma amostra bem maior de municípios, nem quando adicionamos controles. Assim sendo, parece não haver pro- 
blemas sérios em utilizar os dados do FINBRA anteriores a 2002. No painel $\mathrm{B}$, o mesmo modelo é estimado usando os gastos com saúde como variável dependente. Este é um teste adicional para checarmos se a variável "FUNDEF/FUNDEB líquido per capita" pode ser considerada exógena, não tendo afetado outros gastos dos governos municipais que também poderiam impactar diretamente os resultados educacionais. De fato, o efeito do FUNDEF sobre os gastos com saúde é não significativo quando controlamos pelas receitas vinculadas à área de educação.

\subsubsection{Base de Indivíduos}

A Tabela 3 a seguir apresenta as estatísticas descritivas da variável de interesse e das variáveis que definem os resultados das crianças. Entre crianças de 7 a 14 anos, considerando os anos de 2000 e 2010 em conjunto, 97\% frequentavam escola ou creche, o que sugere que o ensino fundamental tornou-se praticamente universal ao longo da década de 1990. A defasagem escolar média era de 0,39 anos, variando de -2 anos a 7 anos. ${ }^{4}$ Já a variável referente ao trabalho infantil indica que, considerando os dois anos em conjunto, cerca de $5 \%$ das crianças de 10 a 14 anos estavam nesta situação. ${ }^{5}$ O "FUNDEF/FUNDEB líquido per capita médio" foi em média de R\$ 198,61, com grande variação entre os indivíduos.

Tabela 3 - Estatísticas descritivas da base de indivíduos - curto-prazo (variáveis de resultado e de interesse)

\begin{tabular}{lccccc}
\hline \multicolumn{1}{c}{ Variáveis } & Obs & Média & Desvio padrão & Máximo & Mínimo \\
\hline \multicolumn{7}{c}{ Variáveis de resultado } \\
\hline Frequência escolar & 27.788 .831 & 0,97 & 0,18 & 0 & 1 \\
Defasagem escolar & 23.812 .482 & 0,39 & 1,24 & -2 & 7 \\
Ocupação & 17.591 .045 & 0,05 & 0,22 & 0 & 1 \\
\hline \multicolumn{7}{c}{ Variável de interesse } \\
\hline FUNDEF líquido per capita médio & 27.788 .831 & 198,61 & 384,95 & $-5.855,61$ & $3.530,10$ \\
\hline
\end{tabular}

Notas: Elaboração própria a partir dos dados do FINBRA (1993 - 2010), Datasus e Censos Demográficos (2000 e 2010).

4 Definimos defasagem escolar como: defasagem escolar=idade-anos de estudo completos-7. Valores negativos desta variável indicam que a criança está em uma série à frente do que seria esperado pela sua idade. Valores positivos indicam que a criança está atrasada.

5 Tal informação só está disponível para os indivíduos com 10 anos ou mais. 
A Tabela 4 apresenta as estatísticas descritivas dos controles usados nos modelos. Importante destacar as variáveis "Proporção de matrículas municipais", sempre referente ao ano de 1995, antes da introdução do FUNDEF; e a dummy que identifica se o responsável pelo domicílio tem ensino fundamental. Ambas serão utilizadas para estimar possíveis efeitos heterogêneos do FUNDEF/FUNDEB segundo participação da rede municipal no município onde a criança mora e background familiar, respectivamente. Considerando os dois Censos, a proporção média de matrículas municipais nas localidades onde moravam era de $30 \%$, enquanto $60 \%$ delas viviam em domicílios cujo responsável não tinha ensino fundamental completo.

Tabela 4 - Estatísticas descritivas da base de indivíduos (variáveis de controle)

\begin{tabular}{lccccc}
\hline Variáveis & Obs & Média & Desvio padrão & Máximo & Mínimo \\
\hline Proporção de matrículas municipais (\% Municipal) & 27.788 .831 & 0,30 & 0,21 & 0 & 1 \\
Dummy para crianças cujo responsável pelo & 27.724 .201 & 0,60 & 0,49 & 0 & 1 \\
domicílio não tem EF completo & & & & & \\
Dummy para mulheres & 27.788 .831 & 0,49 & 0,50 & 0 & 1 \\
Dummy para brancos & 27.673 .775 & 0,52 & 0,50 & 0 & 1 \\
Dummy para meio urbano & 27.788 .831 & 0,86 & 0,35 & 0 & 1 \\
Renda domiciliar per capita & 27.751 .935 & 581,00 & $1.775,44$ & 0 & 795.372 \\
Idade do responsável pelo domićlio & 27.771 .574 & 42,54 & 11,29 & 10 & 132 \\
Densidade morador / dormitório & 27.696 .206 & 2,43 & 1,29 & 1 & 26 \\
Dummy para escoamento adequado de esgoto & 27.788 .831 & 0,66 & 0,47 & 0 & 1 \\
\hline
\end{tabular}

Notas: Elaboração própria a partir dos dados dos Censos Demográficos (2000 e 2010).

Os 3 painéis que compõem o Gráfico 3 abaixo plotam variações nas três variáveis de resultado analisadas neste artigo associadas a variações na exposição das diferentes faixas etárias aos fundos de financiamento. Mais especificamente, para cada uma das três variáveis, em primeiro lugar calculamos a média da variável para cada faixa etária, em cada município e para cada um dos anos de 2000 e 2010. O mesmo cálculo pode ser feito para medir a exposição de cada uma das faixas etárias em cada município ao FUNDEF/FUNDEB. Por fim, plotamos a diferença da média da variável entre 2000 e 2010 (eixo vertical) contra a exposição aos fundos (eixo horizontal). O padrão de correlação encontrado nos três painéis nos ajuda a sintetizar alguns dos resultados encontrados à frente. Em primeiro lugar, encontramos uma associação positiva, mas pequena entre a exposição aos fundos e frequência escolar. Encontramos também uma relação negativa 
e relativamente forte entre os fundos e distorção idade-série. Por fim, o último painel sugere uma associação positiva entre os fundos e trabalho infantil. Como descrito à frente, no entanto, encontramos associação nula entre essas variáveis ao levarmos a análise para as regressões.
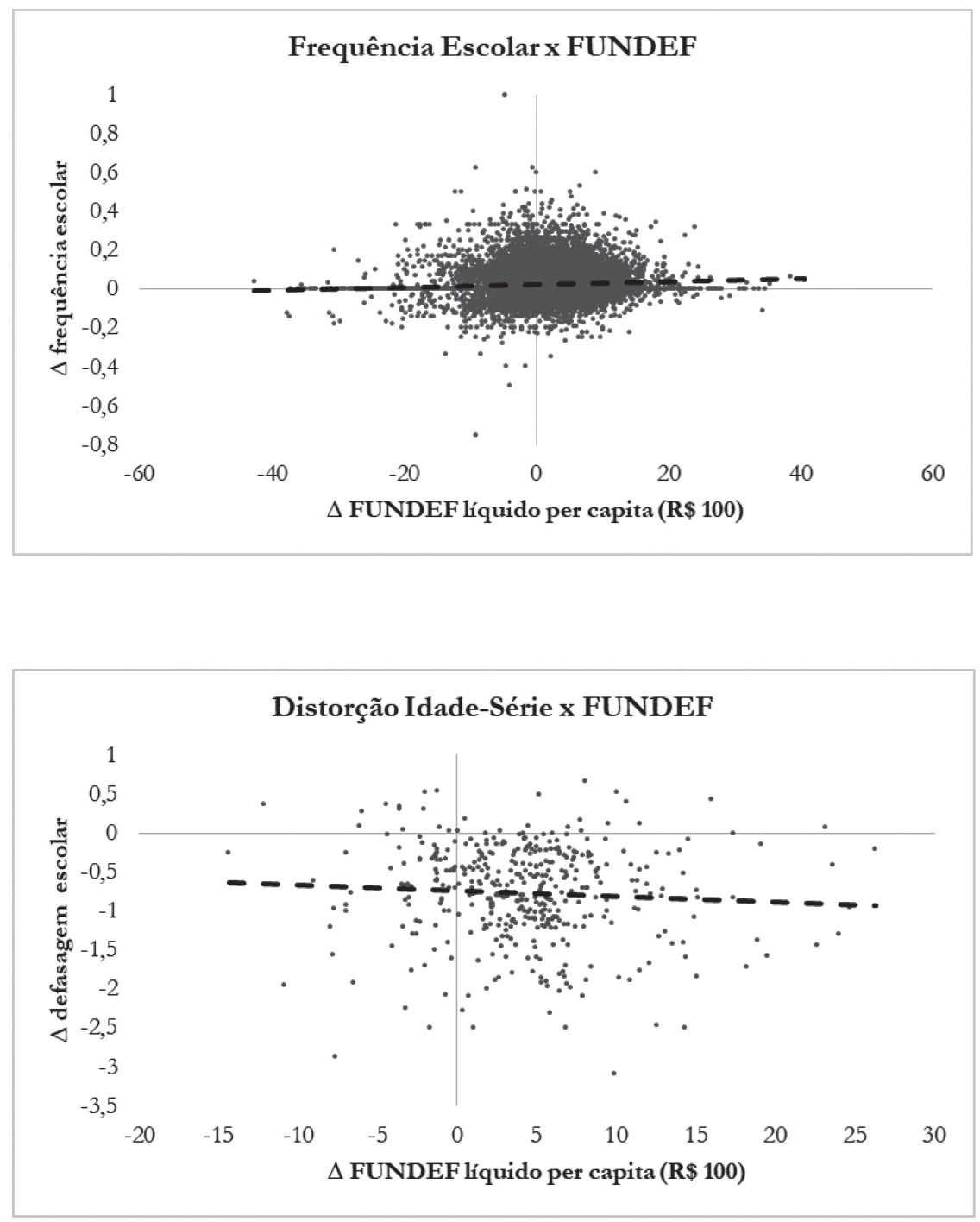


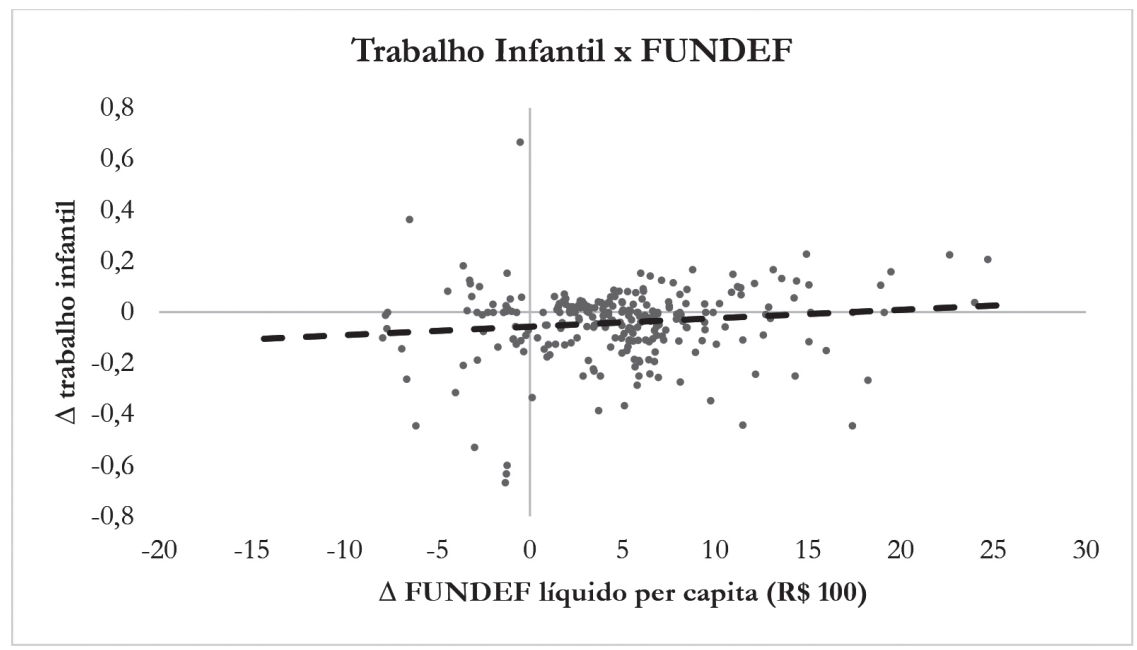

Gráfico 3 - Correlações entre FUNDEF líquido per capita e variáveis de resultado Notas: Elaboração própria a partir dos dados dos Censos 2000 e 2010 e FINBRA (1993 - 2010).

\section{Modelo Empírico}

\subsection{Estratégia Empírica}

Neste artigo, analisamos os impactos do FUNDEF/FUNDEB sobre os resultados das crianças expostas aos fundos. Naturalmente as despesas do governo municipal são em geral consideradas endógenas. O nível do gasto depende tanto das prioridades dos governantes, quanto da receita e consequentemente do nível de renda per capita do município. O montante que cada município recebe via FUNDEF/FUNDEB, por sua vez, depende do número de alunos em sua rede municipal e do valor total arrecadado no estado, o qual é função das receitas dos municípios que o compõem e do próprio governo estadual. Logo, nenhum desses aspectos está fortemente correlacionado às decisões individuais de cada governante ou à receita do município individualmente e podem ser considerados exógenos a este. Já a contribuição para o fundo é uma proporção de determinadas receitas que o município possui. Haveria, portanto, possibilidade de a variável de interesse ser em alguma medida endógena, uma vez que poderia estar ne- 
gativamente correlacionada com a receita total e, consequentemente, com gastos em outras áreas. O que nos propomos a identificar, no entanto, é o efeito dos fundos, em sua forma reduzida, condicional a efeitos-fixos de município e coorte de nascimento. Nesse sentido, exploramos a variação do montante de recursos per capita destinados para educação gerada pela introdução dos fundos ao longo do tempo, condicional a efeitos fixos de tempo e características específicas de municípios constantes no tempo como, por exemplo, sua capacidade de arrecadação e preferências. A variação remanescente na variável de interesse pode ser considerada exógena.

Mais especificamente, os fundos nos permitem comparar indivíduos parecidos, que residem em municípios semelhantes, mas que receberam investimentos em sua educação diferentes segundo a Unidade da Federação e a época em que nasceram. Neste artigo, exploramos a variação na exposição de diferentes indivíduos aos recursos em educação oriundos do FUNDEF e FUNDEB, que ocorre entre municípios e coortes de nascimento. A hipótese de identificação é que, condicional aos efeitos-fixos de município, idade, ano do Censo, e controles, a variação remanescente na variável de interesse é ortogonal a toda e qualquer variação em determinantes latentes das variáveis de resultado. O modelo a ser estimado pode ser descrito através da seguinte equação:

$$
\begin{aligned}
y_{\text {imta }}=\beta_{0}+ & \beta_{1} \text { FUNDEF(B)líq.pc médio }{ }_{m t a} \\
& +\beta_{2} \text { receita educ.p } c_{m t a}+X_{\text {imta }} \beta_{3}+\alpha_{m}+\delta_{t}+\gamma_{a}+\varepsilon_{\text {imta }}
\end{aligned}
$$

onde $i, m, t$ e $a$ indexam, nesta ordem, o indivíduo, o município onde ele vive, o ano do Censo e sua idade. Os dois últimos identificam a coorte de nascimento do indivíduo. Estamos interessados no coeficiente $\widehat{\beta_{1}}$. Como nas regressões a variável "FUNDEF/FUNDEB líquido per capita médio" foi dividida por 100, os coeficientes estimados traduzem o efeito de um aumento de $\mathrm{R} \$ 100,00$ nos recursos líquidos do FUNDEF/FUNDEB per capita sobre o resultado em questão. O termo $X_{\text {imta }}$ é um vetor de variáveis de controle, que inclui características do indivíduo (sexo e cor) e de sua família (localização do domicílio, logaritmo da renda domiciliar per capita, idade e escolaridade do responsável, a razão entre número de moradores e número de dormitórios do domicílio, e a existência de escoamento de esgoto adequado). Os termos $\alpha_{m}, \delta_{t}$ e $\gamma_{a}$ denotam, nesta ordem, os efeitos fixos de município, ano e idade (coorte de nascimento), que visam 
a controlar variáveis não observáveis, mas que são específicas de alguma dessas dimensões. Por fim, $\varepsilon_{i m t a}$ é o termo de erro.

Os efeitos-fixos de município controlam por características não observáveis e específicas de cada município, invariantes no tempo. Naturalmente estes efeitos absorvem efeitos-fixos de Unidades da Federação. O efeito-fixo de ano do censo é representado por uma dummy que indica se a observação é derivada do Censo de 2010. Esta dummy controla tendências comuns a todos os municípios, como o ciclo macroeconômico ou políticas educacionais e gastos públicos que variaram homogeneamente entre municípios no período. Os efeitos-fixos de idade, juntamente com a dummy anterior, nos ajudam a identificar coortes. Portanto, eles absorvem a influência de fatores não observáveis sobre as variáveis de resultado específicas a cada uma das coortes de nascimento.

Para estimar o efeito corretamente, o ideal seria conhecer a rede de ensino na qual cada criança estuda e manter apenas as da rede municipal. No entanto, os dados do Censo não trazem essa informação. Desse modo, o fato de existirem municípios onde a rede municipal ainda é pouco expressiva causaria uma atenuação dos resultados. Mais do que isso, em geral, municípios ganham recursos em termos líquidos em estados onde a proporção de matrículas na rede municipal é maior. Nestes estados, as redes estaduais perdem recursos, ao contrário do que mostrará o valor da variável FUNDEF/FUNDEB líquido per capita médio atribuído aos seus alunos que residem em municípios onde as redes municipais ganharam recursos. Para corrigir este problema, foi incluída uma interação da variável FUNDEF/ FUNDEB líquido per capita médio com a proporção (0 a 1) de alunos do município matriculados na rede municipal no ano base, no caso 1995. Dessa forma, é possível estimar efeitos diferenciados para municípios com diferentes participações da rede municipal no total de vagas ofertadas no Ensino Fundamental.

Outra possível fonte de heterogeneidade é o background familiar da criança. É fato conhecido na literatura internacional (ver Brooke e Soares (2008) para um resumo da evolução da literatura internacional sobre o tema) que crianças com background mais pobre - isto é, com renda familiar menor, pais menos escolarizados etc. - têm resultados escolares inferiores. É possível que, entre essas crianças, políticas educacionais tenham maior impacto, pois há mais espaço para melhorias quando os resultados são piores. Por outro lado, pode ser mais difícil fazer com que as políticas cheguem a essas crianças, dadas as limitações impostas pelas condições 
precárias em que muitas delas vivem. Para investigar a possível ocorrência dessas diferenças, foi introduzida no modelo uma interação tripla, que envolve a variável FUNDEF/FUNDEB líquido per capita médio, a proporção de matrículas municipais no município onde a criança vive e uma dummy que identifica se o responsável pelo domicílio da criança tem ou não Ensino Fundamental completo. Esta última é a variável escolhida para traduzir o background familiar.

\subsection{Potenciais Problemas de Identificação e Fontes de Viés}

Como mencionado anteriormente, os dados do FINBRA são declarados pelos próprios municípios, podendo haver erros de declaração, principalmente nos dados anteriores a 2002. Quando tais erros são aleatórios, eles tendem a atenuar os efeitos estimados. Comparando a relação entre o FUNDEF/FUNDEB e os gastos em educação nos períodos de 1996 a 2010 e de 2002 a 2010 (Seção 3, Tabela 2), verificou-se que os erros de declaração não são relevantes para o nosso estudo.

Outra fonte de preocupação refere-se à relação entre o ciclo econômico próprio de cada Unidade da Federação e a variável de interesse em nível estadual. Se a correlação entre a variável $F U N D E F(B) l i ́ q . p c$ médio $o_{m t a}$ e a receita das Unidades da Federação, mantidos constantes todos os outros controles, é positiva ao longo do tempo, os efeitos poderão estar superestimados. Se, ao contrário, essa correlação é negativa, os impactos estarão subestimados. Para os modelos da Seção 3 estimados com base na amostra de municípios de 2002 a 2010, foi possível adicionar um controle para o PIB estadual, que pode ser uma boa proxy para a dinâmica econômica e as receitas de cada estado. Ao fazer isso, os coeficientes estimados não se alteram muito, o que nos traz um indício de que esta possível fonte de viés não é relevante.

Por fim, a introdução da proporção de matrículas municipais e sua interação com a variável de interesse não corrige outra fonte de atenuação dos efeitos, que é a descentralização e seus impactos sobre o desempenho dos alunos, apontada em trabalhos como Franca (2013). Conforme mostram D'atri (2007) e Leme, Paredes e Souza (2009), a instituição dos fundos de financiamento da educação básica, em especial do FUNDEF, causaram, além de um aumento do gasto na área, o aumento da proporção das ma- 
trículas na rede municipal em relação ao total de matrículas. É possível, segundo esses autores, que tal processo tenha desorganizado, ao menos inicialmente, as redes de ensino e a gestão das escolas. Desse modo, haveria dois fatores associados ao FUNDEF/FUNDEB atuando em sentidos contrários: o aumento do gasto em educação por um lado, e a municipalização por outro, o que atenuaria os efeitos que estamos procurando.

\section{Resultados}

Nesta seção são apresentados os resultados sobre frequência escolar, defasagem idade-série e trabalho infantil. Foram estimados modelos com amostra balanceada (segundo os municípios ao longo do tempo) e não balanceada; e com amostra considerando apenas as crianças cuja condição no domicílio é filho vs amostra total de crianças. Os resultados apontam sempre na mesma direção. Por conta disso, a seguir serão apresentados os resultados para a amostra balanceada e considerando todas as crianças, independente da condição no domicílio. Na segunda subseção, são estimados modelos que controlam a heterogeneidade dos efeitos segundo escolaridade do responsável pelo domicílio.

\subsection{Resultados Principais}

A Tabela 5 apresenta os resultados dos efeitos estimados para frequência escolar. Na primeira coluna regredimos uma variável que indica se a criança frequenta a escola sobre a variável de interesse, condicional a efeitosfixos de municípios, coortes e ano do Censo. Nas colunas 3 e 5, respectivamente, adicionamos controles socioeconômicos e a variável de receita, que corresponde ao valor que os municípios devem, obrigatoriamente, destinar à educação, dividido pelo público alvo da educação básica. Nas colunas 2 , 4 e 6 introduzimos uma variável de interação entre a variável de interesse e a proporção de matrículas na rede municipal em 1995, ano inicial do FUNDEF. Em todas as regressões os erros-padrão são estimados em cluster e robustos à autocorrelação serial ao nível dos municípios, ao longo do tempo. Observa-se um efeito positivo e significativo do recebimento de recursos líquidos via FUNDEF/FUNDEB. Os modelos sem a interação 
entre a variável de interesse e a proporção de matrículas na rede municipal no ano base revelam que, a cada $\mathrm{R} \$ 100$ a mais do FUNDEF, observa-se um aumento médio de 0,07 a 0,10 pontos percentuais na probabilidade de a criança frequentar escola. Já nas colunas que consideram a interação, a interpretação depende dos dois coeficientes. Para municípios com 100\% das matrículas municipais, o efeito estimado nas colunas 2, 4 e 6 é muito (mais de quatro vezes) maior ao obtido a partir dos modelos sem a interação, conforme o esperado. Para esses municípios, R\$100 a mais de FUNDEF implica uma probabilidade de 0,31 a 0,41 pontos percentuais maior de uma criança frequentar a escola. Fazendo o cálculo para a mediana da proporção de matrículas municipais de 1995, 26,6\%, o efeito varia entre 0,05 a 0,07 pontos percentuais. Tomando as estimações da coluna 6 como base, o aumento de um desvio-padrão nos recursos líquidos do FUNDEF, $\mathrm{R} \$ 384,95$, gera um aumento da frequência escolar de $6,5 \%$ de um desvio -padrão, considerando a proporção de matrículas municipais igual a 100\%, e de $1,0 \%$ considerando-a igual à mediana. $\mathrm{O}$ efeito é expressivo dada a quase universalidade do Ensino Fundamental.

Tabela 5 - Efeitos sobre frequência escolar

\begin{tabular}{|c|c|c|c|c|c|c|}
\hline \multicolumn{7}{|c|}{ Variável dependente: Frequência escolar } \\
\hline & (1) & (2) & (3) & (4) & (5) & (6) \\
\hline \multirow[t]{2}{*}{ FUNDEF/B } & 0,0010 & $-0,0005$ & 0,0009 & $-0,0004$ & 0,0007 & $-0,0005$ \\
\hline & $(0,0002)^{\star \star *}$ & $(0,0003)^{*}$ & $(0,0002)^{\star \star \star}$ & $(0,0003)^{*}$ & $(0,0002)^{\star \star \star}$ & $(0,0002)^{\star \star *}$ \\
\hline \multirow[t]{2}{*}{$\begin{array}{l}\text { FUNDEF/B * (\% } \\
\text { Municipal) }\end{array}$} & & 0,0046 & & 0,0041 & & 0,0036 \\
\hline & & $(0,0015)^{\star \star *}$ & & $(0,0012)^{\star * *}$ & & $(0,0007)^{\star * *}$ \\
\hline № obs & 2.966 .199 & 2.966 .199 & 2.966 .199 & 2.966 .199 & 2.966 .199 & 2.966 .199 \\
\hline № de municípios & 2.920 & 2.920 & 2.920 & 2.920 & 2.920 & 2.920 \\
\hline $\mathrm{R}^{2}$ & 0,0172 & 0,0175 & 0,0292 & 0,0294 & 0,0297 & 0,0298 \\
\hline Controles & Não & Não & Sim & Sim & Sim & Sim \\
\hline Receita & Não & Não & Não & Não & Sim & Sim \\
\hline
\end{tabular}

Notas: Elaboração própria a partir dos dados do FINBRA (1993 - 2010), Datasus e Censos Demográficos (2000 e 2010). Todas as especificações incluem efeitos fixos de idade, ano e município. As variáveis de controle consideradas são dummy que identifica se o responsável pelo domicílio tem Ensino Fundamental, sexo, cor, localização do domicílio, logaritmo da renda domiciliar per capita, idade do responsável pelo domicílio, razão entre número de moradores e número de dormitórios do domicílio, e existência de escoamento de esgoto adequado. Erros padrões entre parênteses e nível de significância indicado: *** $\mathrm{p}<0,01,{ }^{* *} \mathrm{p}<0,05,{ }^{*} \mathrm{p}<0,1$. 
Os efeitos seguem no mesmo sentido no caso da defasagem idade-série, diminuindo com a adição de controles e aumentando com a incorporação da interação ao modelo. Nos modelos sem interação, encontra-se um efeito negativo em torno de -0,03 anos de defasagem escolar diante de um aumento de R\$ 100 no FUNDEF. Já nos modelos com a interação, encontrase um efeito de aproximadamente $-0,1$ para municípios onde a totalidade das matrículas da rede pública é municipal, e de -0,02 para aqueles com $26,5 \%$ das matrículas municipais. Tal efeito é bem mais expressivo do que para a frequência escolar, considerando a média $(0,39)$ e o desvio-padrão $(1,24)$ da variável. Segundo a estimação da coluna 6 , o aumento de um desvio-padrão dos recursos do FUNDEF causa uma redução da defasagem de $28 \%$ de um desvio-padrão para municípios onde 100\% das crianças estudam em escolas municipais, e de $6,5 \%$ de um desvio-padrão para os municípios medianos, onde a proporção de matrículas na rede municipal é bem mais baixa.

Tabela 6 - Efeitos sobre defasagem escolar

\begin{tabular}{|c|c|c|c|c|c|c|}
\hline & \multicolumn{6}{|c|}{ Variável dependente: Defasagem escolar } \\
\hline & (1) & (2) & (3) & (4) & (5) & (6) \\
\hline \multirow[t]{2}{*}{ FUNDEF/B } & $-0,0305$ & 0,0038 & $-0,0302$ & 0,0032 & $-0,0263$ & 0,0040 \\
\hline & $(0,0038)^{\star * *}$ & $(0,0062)$ & $(0,0036)^{\star * *}$ & $(0,0057)$ & $(0,0034)^{\star \star *}$ & $(0,0048)$ \\
\hline \multirow[t]{2}{*}{ FUNDEF/B * (\% Municipal) } & & $-0,1054$ & & $-0,1026$ & & $-0,0941$ \\
\hline & & $(0,0271)^{\star \star \star}$ & & $(0,0240)^{\star * *}$ & & $(0,0163)^{\star \star *}$ \\
\hline № obs & 2.551 .274 & 2.551 .274 & 2.551 .274 & 2.551 .274 & 2.551 .274 & 2.551 .274 \\
\hline № de municípios & 2.920 & 2.920 & 2.920 & 2.920 & 2.920 & 2.920 \\
\hline $\mathrm{R}^{2}$ & 0,2711 & 0,274 & 0,3228 & 0,3255 & 0,3254 & 0,3277 \\
\hline Controles & Não & Não & Sim & Sim & Sim & Sim \\
\hline Receita & Não & Não & Não & Não & Sim & Sim \\
\hline
\end{tabular}

Notas: Elaboração própria a partir dos dados do FINBRA (1993 - 2010), Datasus e Censos Demográficos (2000 e 2010). Todas as especificações incluem efeitos fixos de idade, ano e município. As variáveis de controle consideradas são dummy que identifica se o responsável pelo domicílio tem Ensino Fundamental, sexo, cor, localização do domicílio, logaritmo da renda domiciliar per capita, idade do responsável pelo domicílio, razão entre número de moradores e número de dormitórios do domicílio, e existência de escoamento de esgoto adequado. Erros padrões entre parênteses e nível de significância indicado: *** $\mathrm{p}<0,01,{ }^{* *} \mathrm{p}<0,05,{ }^{*} \mathrm{p}<0,1$. 
Como a defasagem escolar é calculada apenas para os alunos que frequentam escola, pode existir viés de seleção, não corrigido pelo modelo aqui estimado. Ao contribuir para o aumento da frequência escolar, é provável que o FUNDEF também seja responsável pela incorporação de alunos potencialmente de pior rendimento ao sistema de ensino, o que faria os indicadores médios de fluxo escolar piorarem nos municípios mais beneficiados pelo fundo. Nesse caso, temos uma fonte adicional de viés de atenuação, o que torna os resultados encontrados ainda mais expressivos.

Tabela 7 - Efeitos sobre trabalho infantil

\begin{tabular}{|c|c|c|c|c|c|c|}
\hline & \multicolumn{6}{|c|}{ Variável dependente: Ocupação } \\
\hline & (1) & (2) & (3) & (4) & (5) & (6) \\
\hline \multirow[t]{2}{*}{ FUNDEF/B } & -0.0003 & 0.0007 & -0.0004 & 0.0006 & -0.0002 & 0.0007 \\
\hline & $(0,0003)$ & $(0,0003)^{\star \star}$ & $(0,0002)^{*}$ & $(0,0003)^{\star \star}$ & $(0,0002)$ & $(0,0003)^{\star \star}$ \\
\hline \multirow[t]{2}{*}{ FUNDEF/B * (\% Municipal) } & & -0.0027 & & -0.0028 & & -0.0022 \\
\hline & & $(0,0011)^{\star \star}$ & & $(0,0011)^{\star * \star}$ & & $(0,0007)^{\star * *}$ \\
\hline № obs & $1,869,553$ & $1,869,553$ & $1,869,553$ & $1,869,553$ & $1,869,553$ & $1,869,553$ \\
\hline № de municípios & 2,920 & 2,920 & 2,920 & 2,920 & 2,920 & 2,920 \\
\hline $\mathrm{R}^{2}$ & 0.062 & 0.0621 & 0.0769 & 0.0769 & 0.0771 & 0.0771 \\
\hline Controles & Não & Não & Sim & Sim & Sim & Sim \\
\hline Receita & Não & Não & Não & Não & Sim & Sim \\
\hline
\end{tabular}

Notas: Elaboração própria a partir dos dados do FINBRA (1993 - 2010), Datasus e Censos Demográficos (2000 e 2010). Todas as especificações incluem efeitos fixos de idade, ano e município. As variáveis de controle consideradas são dummy que identifica se o responsável pelo domicílio tem Ensino Fundamental, sexo, cor, localização do domicílio, logaritmo da renda domiciliar per capita, idade do responsável pelo domicílio, razão entre número de moradores e número de dormitórios do domićlio, e existência de escoamento de esgoto adequado. Erros padrões entre parênteses e nível de significância indicado: *** $\mathrm{p}<0,01,{ }^{* *} \mathrm{p}<0,05,{ }^{*} \mathrm{p}<0,1$.

Em relação ao trabalho infantil, os resultados em geral são não significativos nos modelos sem a interação. Nos modelos com a interação, tanto os coeficientes desta quanto os coeficientes da variável FUNDEF/B são significativos: o efeito total é negativo para município com 100\% das matrículas municipais, variando de $-0,22$ a $-0,15$ pontos percentuais; e muito pequeno para os municípios medianos, sendo sua direção incerta. Em geral, a estimação dos modelos com a interação entre a variável de interesse e a proporção de alunos matriculados na rede municipal no ano base sempre segue a tendência esperada: os efeitos encontrados são mais fortes nos 
municípios onde a proporção de alunos da rede municipal era inicialmente maior, mas são quase inexistentes onde a rede era pouco expressiva. Importante mencionar que, do ponto de vista qualitativo, todos os resultados principais descritos nesta seção são robustos na ausência de interação com a cobertura municipal - efeitos pequenos e positivos sobre frequência, negativo sobre defasagem, e nulo sobre trabalho infantil (como mostram as colunas 5 das Tabelas 5, 6 e 7). O coeficiente da interação nos dá a forma reduzida de um efeito importante - nos diz que municípios com uma rede municipal mais desenvolvida no início da política obtiveram melhores resultados. Por um lado, isso pode ser devido ao fato de que a proporção de crianças expostas aos recursos era maior nestes municípios desde o início das transferências. Por outro, por terem uma rede municipal originalmente mais desenvolvida, o processo de municipalização foi relativamente menos intenso nestes municípios. Como mencionamos na Seção 4.2, é possível que a municipalização tenha desorganizado, ao menos inicialmente, as redes de ensino e a gestão das escolas. Desse modo, haveria dois fatores associados ao FUNDEF/FUNDEB atuando em sentidos contrários: o aumento do gasto em educação por um lado, e a municipalização por outro, o que atenuaria os efeitos estimados. Novamente, neste caso devemos observar efeitos maiores em municípios que tinham originalmente uma rede municipal já mais desenvolvida.

\subsection{Heterogeneidade segundo Background Familiar}

Políticas sociais costumam ter efeitos heterogêneos para diferentes grupos de indivíduos. No caso das políticas educacionais, uma importante fonte de heterogeneidade é o background familiar: a depender da escolaridade dos pais, da renda domiciliar e de outros fatores relacionados à família, as crianças podem se beneficiar mais ou menos de determinadas políticas. Crianças de background pior podem se beneficiar mais por serem as que apresentam resultados incialmente piores, havendo mais espaço para melhorá-los. Por outro lado, o background pior pode ser um obstáculo ao funcionamento da política. Nesta seção, analisamos a possibilidade de os efeitos encontrados anteriormente serem diferentes para dois grupos de crianças: aquelas que vivem em domicílios cujo responsável não tem ensino fundamental completo; e as que vivem em domicílios cujo responsável completou esse nível de ensino. A escolha da variável de educação do chefe do domicílio deve-se ao fato de que esta pode ser considerada uma proxy para renda permanente. 
A Tabela 8 compara as estimações que acrescentam a interação com a dummy que identifica a escolaridade do responsável pelo domicílio e as estimações anteriores. As colunas 1, 3 e 5 apresentam, novamente, os resultados das colunas 6 das três tabelas anteriores. Já as colunas 2, 4 e 6 trazem os resultados das novas estimações. No painel A, são apresentados os resultados das regressões, enquanto, no painel $\mathrm{B}$, apresentamos o efeito total (e seu nível de significância) do aumento de R\$100 do FUNDEF/B líquido per capita sobre os dois grupos de crianças em questão.

Tabela 8 - Efeitos sobre os resultados das crianças, controlado pelo background familiar

\begin{tabular}{|c|c|c|c|c|c|c|}
\hline & \multicolumn{2}{|c|}{ Frequência escolar } & \multicolumn{2}{|c|}{ Defasagem idade-série } & \multicolumn{2}{|c|}{ Trabalho infantil } \\
\hline & (1) & (2) & (3) & (4) & (5) & (6) \\
\hline & \multicolumn{6}{|c|}{ Painel A - Resultados das regressões } \\
\hline \multirow[t]{2}{*}{ FUNDEF/B } & $-0,0005$ & $-0,0005$ & 0,004 & 0,0053 & 0,0007 & 0,001 \\
\hline & $(0,0002)^{\star * \star}$ & $(0,0002)^{\star * *}$ & $(0,0048)$ & $(0,0069)$ & $(0,0003)^{* *}$ & $(0,0003)^{* * *}$ \\
\hline \multirow[t]{2}{*}{ FUNDEF/B * (\% Municipal) } & 0,0036 & 0,0021 & $-0,0941$ & $-0,0575$ & $-0,0022$ & $-0,0014$ \\
\hline & $(0,0007)^{\star \star \star}$ & $(0,0007)^{\star \star *}$ & $(0,0163)^{\star \star \star}$ & $(0,0208)^{\star \star \star}$ & $(0,0007)^{\star \star \star}$ & $(0,0007)^{\star *}$ \\
\hline \multirow[t]{2}{*}{ FUNDEF/B * (chefe sem EF) } & & 0,0002 & & $-0,0058$ & & $-0,0007$ \\
\hline & & $(0,0002)$ & & $(0,0049)$ & & $(0,0002)^{\star \star \star}$ \\
\hline \multirow{2}{*}{$\begin{array}{l}\text { FUNDEF/B * (\% Municipal) * } \\
\text { (chefe sem EF) }\end{array}$} & & 0,0018 & & $-0,043$ & & $-0,0008$ \\
\hline & & $(0,0004)^{\star \star \star}$ & & $(0,0130)^{\star * *}$ & & $(0,0007)$ \\
\hline № obs & 2.966 .199 & 2.966 .199 & 2.551 .274 & 2.551 .274 & 1.869 .553 & 1.869 .553 \\
\hline \multirow[t]{2}{*}{ № de municípios } & 2.920 & 2.920 & 2.920 & 2.920 & 2.920 & 2.920 \\
\hline & \multicolumn{6}{|c|}{$\begin{array}{l}\text { Painel } B \text { - Efeitos totais de um aumento de } \mathrm{R} \$ 100,00 \text { no FUNDEF líquido per capita } \\
\text { (p-valor entre parênteses), considerando } \% \text { municipal }=0,2662 \text { (mediana) }\end{array}$} \\
\hline \multirow[t]{2}{*}{ Efeito com chefe sem EF } & & 0,0007 & & $-0,0273$ & & $-0,0003$ \\
\hline & 0,0005 & $(0,0001)$ & $-0,0210$ & $(0,0000)$ & 0,0001 & $(0,2447)$ \\
\hline \multirow[t]{2}{*}{ Efeito com chefe com EF } & $(0,0068)$ & 0,0000 & $(0,0000)$ & $-0,0100$ & $(0,7728)$ & 0,0006 \\
\hline & & $(0,8687)$ & & $(0,0696)$ & & $(0,0074)$ \\
\hline
\end{tabular}

Notas: Elaboração própria a partir dos dados do FINBRA (1993 - 2010), Datasus e Censos Demográficos (2000 e 2010). Todas as especificações incluem efeitos fixos de idade, ano e município. Foram feitas todas as interações entre as variáveis FUNDEF (B) líq. pc, proporção de matrículas municipais, e chefe sem EF. As variáveis de controle consideradas são dummy que identifica se o responsável pelo domicílio tem Ensino Fundamental, sexo, cor, localização do domicílio, logaritmo da renda domiciliar per capita, idade do responsável pelo domicílio, razão entre número de moradores e número de dormitórios do domicílio, e existência de escoamento de esgoto adequado. Painel A: Erros padrões entre parênteses e nível de significância indicado: ${ }^{* *} \mathrm{p}<0,01,{ }^{* *} \mathrm{p}<0,05,{ }^{*} \mathrm{p}<0,1$. Painel B: p-valor entre parênteses. 
Todos os coeficientes relativos à interação tripla entre FUNDEF, a cobertura da rede municipal e a dummy que identifica a escolaridade do responsável pelo domicílio são significativos e apontam para efeitos maiores entre as crianças de pior background (responsável sem ensino fundamental). No caso da frequência escolar, o efeito encontrado é positivo apenas para as crianças cujo responsável pela família não tem ensino fundamental. Provavelmente, entre aquelas com responsáveis mais escolarizados, que correspondem a $40 \%$ da amostra, a frequência escolar já estava próxima de $100 \%$ mesmo antes do FUNDEF. O efeito total, que no modelo sem essa interação tripla era de 0,05 pontos percentuais para toda a amostra, é de 0,07 pontos percentuais para as crianças de pior background no novo modelo. Em termos de desvio-padrão, o aumento de um desvio nos recursos per capita do FUNDEF/FUNDEB causa um aumento da frequência escolar de $1,4 \%$ de um desvio-padrão para municípios cuja proporção de matrículas municipais é igual à mediana.

O efeito sobre a defasagem escolar também difere entre os dois grupos, embora menos. O efeito negativo sobre os alunos de pior background é altamente significativo. Um aumento de R $\$ 100$ do FUNDEF corresponde a uma redução da defasagem de 0,03 anos. Esse efeito negativo é de 0,01 para as demais crianças, e significativo apenas ao nível de significância de 10\%. Em termos de desvio-padrão, o aumento de um desvio na variável de interesse causa uma redução de $8,5 \%$ de desvio-padrão entre aqueles cujos responsáveis pelo domicílio são menos escolarizados. Por fim, os efeitos sobre trabalho infantil são negativos, mas insignificantes entre as crianças de pior background. Ao contrário do esperado, porém, o efeito é positivo (o aumento dos recursos do FUNDEF/B aumenta a ocorrência de trabalho infantil) entre aquelas de melhor background. Este resultado não é robusto, no entanto (significativo apenas ao nível de 10\%).

Portanto, é importante considerar a heterogeneidade de efeitos segundo o background familiar da criança. Para os efeitos mais significativos encontrados na subseção anterior, sobre frequência escolar e defasagem idade-série, os modelos com a interação tripla mostraram que são as crianças de pior background as que mais se beneficiam dos aumentos dos recursos para a educação. Logo, além do efeito positivo geral da redistribuição dos recursos entre os municípios e do aumento dos gastos com educação proporcionados pelo FUNDEF e o FUNDEB, parece existir um importante impacto no sentido de equalizar as oportunidades e os resultados educacionais. 


\section{Considerações Finais}

O presente artigo contribui para a literatura ao estimar os impactos dos fundos de financiamento da educação básica sobre resultados educacionais e trabalho infantil a partir dos Censos Demográficos de 2000 e 2010. Os resultados encontrados até então sobre os impactos do aumento do gasto provocado pelo FUNDEF/FUNDEB apontavam, em geral, para efeitos positivos sobre matrículas e fluxo escolar; e efeitos não conclusivos sobre desempenho. Em geral a literatura existente tem utilizado microdados do sistema educacional disponibilizados pelo MEC/INEP, o que por consequência não nos permite observar o que ocorre com crianças (e famílias) que estão fora do sistema. Neste artigo nos concentramos sobre o impacto dos fundos sobre frequência escolar, distorção idade-série e trabalho infantil a partir dos microdados dos Censos Demográficos. Isso nos permitiu não apenas identificar de fato o efeito dos fundos sobre a margem extensiva da demanda educacional, e sobre trabalho infantil, como também caracterizar heterogeneidades do efeito para perfis socioeconômicos distintos de famílias e crianças. Por sua vez, isso nos permitiu documentar um viés de seleção sobre frequência escolar após a introdução dos fundos.

Os resultados apontaram para efeitos positivos do aumento dos recursos transferidos via FUNDEF/FUNDEB sobre a frequência escolar e a defasagem idade-série. Esses efeitos são, como esperado, maiores nos municípios onde a proporção de matrículas na rede municipal era inicialmente maior. Os efeitos sobre trabalho infantil são, em geral, próximos a zero. Mais precisamente, para os municípios cuja proporção de matrículas municipais era igual à mediana em 1995, encontramos que o aumento em um desvio -padrão nas transferências líquidas do FUNDEF/FUNDEB (R \$385 per capita) implica um aumento de $1 \%$ de desvio-padrão na frequência escolar, ou aproximadamente 0,2 pontos percentuais. Isso representa $3 \%$ da diferença na frequência escolar média entre 1999 e 2009 para crianças de 7 a 14 anos de idade no Brasil (diferença de 6,5 pontos percentuais, de acordo com o Ipeadata). Encontramos também que um aumento de um desvio -padrão nas transferências líquidas do FUNDEF/FUNDEB está associado a uma redução de $6,5 \%$ de um desvio-padrão na distorção idade-série, ou aproximadamente 0,08 anos. Isso representa $20 \%$ da média do indicador de distorção idade-série em nossa amostra, em 0,39 anos. Nossos resultados são consistentes com Gordon e Vegas (2005) e Franco e Menezes-Filho (2010), que encontram efeitos positivos sobre matrículas e fluxo escolar. 
Em relação aos efeitos diferenciados segundo a escolaridade do responsável pelo domicílio, os resultados mostram que são as crianças de status socioeconômico mais baixo (responsáveis sem ensino fundamental) as que mais se beneficiam do aumento dos recursos destinados à educação, resultado que também corrobora as conclusões da literatura apresentada por Gibbons e Mcnally (2013). Para estas crianças, estimamos que o efeito sobre frequência e defasagem escolar é significativo e muito superior ao efeito total, enquanto que, para as crianças cujos responsáveis têm ensino fundamental completo (cerca de $40 \%$ da amostra), os efeitos são não significativos. Parece, portanto, que além do impacto positivo sobre os indicadores de frequência e fluxo em geral, a redistribuição dos recursos via FUNDEF/ FUNDEB tem também um efeito de equalizar os resultados das crianças, o que significa equalizar ao menos parte das oportunidades que são oferecidas a elas. Este é um aspecto importante em termos de formulação de políticas públicas, tendo em vista que a transferência de recursos via FUNDEF/FUNDEB beneficia, principalmente, as crianças de famílias com status socioeconômico mais baixo, que são as mais vulneráveis e as com piores resultados educacionais. Estes resultados são consistentes com estudos que analisaram o impacto dos fundos sobre o desempenho dos alunos em testes padronizados (Gordon e Vegas 2005; Franco e Menezes-Filho 2010; Franca 2013) e encontram efeitos negativos. Neste caso, a progressiva inclusão de novos alunos com status socioeconômico mais baixo ao sistema, como documentado no presente artigo, pode ser responsável pela diminuição da média da proficiência em geral. 


\section{Referências}

Anuatti-Neto, Francisco, Reynaldo Fernandes and Elaine T. Pazello. 2004. "Avaliação dos salários dos professores da rede pública de Ensino Fundamental em tempos de FUNDEF". Revista de Economia Aplicada 8-3: 413-437.

Barros, Ricardo P. de; Rosane Mendonça, Daniel D. dos Santos, and Giovani Quintaes. 2001. "Determinantes do desempenho educacional no Brasil". Pesquisa e Planejamento Econômico 31-1: 1-42.

Brasil. 1988. Constituição da República Federativa do Brasil. Acesso em: 20 ago. 2014. http://www.senado.gov. $\mathrm{br} /$ legislacao/const/.

Brooke, Nigel, and José Francisco Soares, orgs. 2008. Pesquisa em eficácia escolar: origem e trajetórias. Belo Horizonte: Editora UFMG.

Cascio, Elizabeth U., Sarah Reber. 2013. "The poverty gap in school spending following the introduction of title 1”. The American Economic Review: Papers \& Proceedings, 103(3): 423-427.

Chetty, Raj, John N. Friedman, and Jonah E. Rockoff. 2013. "Measuring the impacts of teachers II: teacher value-added and student outcomes in adulthood". American Economic Review 104-9: 2633-2679.

Coleman, James, Ernest Campbell, Carol Hobson, James McPartland, Alexander Mood, Frederic Weinfeld, and Robert York. 1966. Equality of Educational Opportunity. Washington, D. C: Government Printing Office.

D’atri, Fabiana. 2007. “Municipalização do Ensino Fundamental da rede pública: os impactos sobre o desempenho escolar”. Dissertação (Mestrado em Economia), Escola de Economia de São Paulo - Fundação Getúlio Vargas.

Duflo, Esther. 2001. "Schooling and labor market consequences of school construction in Indonesia: evidence from an unusual policy experiment". American Economic Review 91- 4: 795 - 813.

Franca, Maíra A. P. 2013. "Financiamento e qualidade da educação básica no Brasil: evidências a partir do FUNDEB". Dissertação (Mestrado em Economia), Centro de Ciências Sociais Aplicadas - Universidade Federal Fluminense.

Franco, Ana Maria de P., and Naercio A. Menezes-Filho. "Os impactos do FUNDEF sobre indicadores educacionais". Artigo apresentado no XXXVIII Encontro Nacional de Economia (ANPEC), Salvado, Bahia, 7-10 dezembro, 2010.

Gibbons, Stephen and Sandra McNally. 2013. "The effects of resources across school phases: a summary of recent evidence". Center for Economic Performance. Discussion Paper, $\mathrm{n}^{\circ}$ 1.226: 1 - 35.

Gordon, Nora, and Emiliana Vegas. 2005. "Education finance equalization, spending, teacher quality and student outcomes: the case of Brazil's FUNDEF”. In: Vegas, Emiliana (ed.). 2005. Incentives to Improve Teaching. Washington DC: The World Bank. 151-186.

Guimarães, José Luiz. 2005. “Do FUNDEF ao FUNDEB: Uma Breve Reflexão sobre as Recentes Mudanças no Financiamento da Educação Brasileira”. Pedagogia Cidadã Cadernos de Formação Legislação Educacional 1-1.

Hanushek, Eric A. 2003. "The failure of input-based schooling policies”. The Economic Journal, n 113: 64 - 98. Instituto Brasileiro de Geografia e Estatística (IBGE). Censos Demográficos de 2000 e 2010.

Instituto de Pesquisa Econômica Aplicada (IPEA). IpeaData.

Instituto Nacional de Estudos e Pesquisas Educacionais Anísio Teixeira (INEP). Censo Escolar, 1995 a 2010.

Jackson, C. Kirabo; Rucker C. Johnson, and Claudia Persico. 2016. "The effects of school spending on educational and economic outcomes: evidence from school finance reforms". The Quarterly Journal of Economics, 131(1): 157-218.

Krueger, Alan. B. 2002.” Economic considerations and class size”. National Bureau of Economic Research. Working Paper, $n^{\circ} 8.875$. 
Leme, Maria Carolina, Ricardo Paredes, and André P. Souza. 2009. “A municipalização do ensino fundamental e seu impacto sobre a proficiência no Brasil". In: Veloso, Fernando; Pessoa, Samuel; Henriques, Ricardo; Giambiagi, Fábio. (org.). Educação Básica no Brasil. Rio de Janeiro: Campus/Elsevier: v. 1, 261-280.

Madeira, Ricardo. "The effect of decentralization on schooling: evidence from São Paulo state's education reform." Artigo apresentado na Northeast Universities Development Consortium (NEUDC) Conference, Cambridge, Massachusetts, 26-27 Outubro, 2007.

Menezes-Filho, Naercio, and Elaine Pazello. 2007. 'Do teachers' wages matter for proficiency? Evidence from a funding reform in Brazil". Economics of Education Review 26: 660-672.

Roy, Joydeep. 2011. "Impact of school finance reform on resource equalization and academic performance: evidence from Michigan". Journal Education Finance and Policy, 6: 137 - 167.

Secretaria do Tesouro Nacional (STN). Finanças do Brasil (FINBRA). 